\title{
Correction to: Networks, Anomy and Open Innovation: Some Conceptual Views
}

\section{Jochen Wittmann}

Die Zugehörigkeit zum Autor Jochen Wittmann wird in diesem Kapitel falsch erfasst. Die korrekte Zugehörigkeit sollte Entwicklungszentrum, Weissach sein. Dies wurde korrigiert.

Die aktualisierte Originalversion dieses Kapitels finden Sie unter https://doi.org/10.1007/978-3-658-03462-7_27.

(C) Springer Fachmedien Wiesbaden 2021

W. Kersten et al. (eds.), Kompetenz, Interdisziplinarität und Komplexität in der Betriebswirtschaftslehre, 